\title{
Meia lua Falciforme: poesia, dor e luta
}

\section{Meia lua Falciforme: poetry, pain and battles \\ Meia lua Falciforme: poesía, dolor y lucha}

Winnie Samanú de Lima Lopes ${ }^{1, a}$

winnie.samanu@gmail.com | https://orcid.org/0000-0003-2433-0103

${ }^{1}$ Fundação Oswaldo Cruz, Instituto Fernandes Figueira. Rio de Janeiro, RJ, Brasil.

a Mestre em Antropologia Médica pela Universidade de Coimbra.

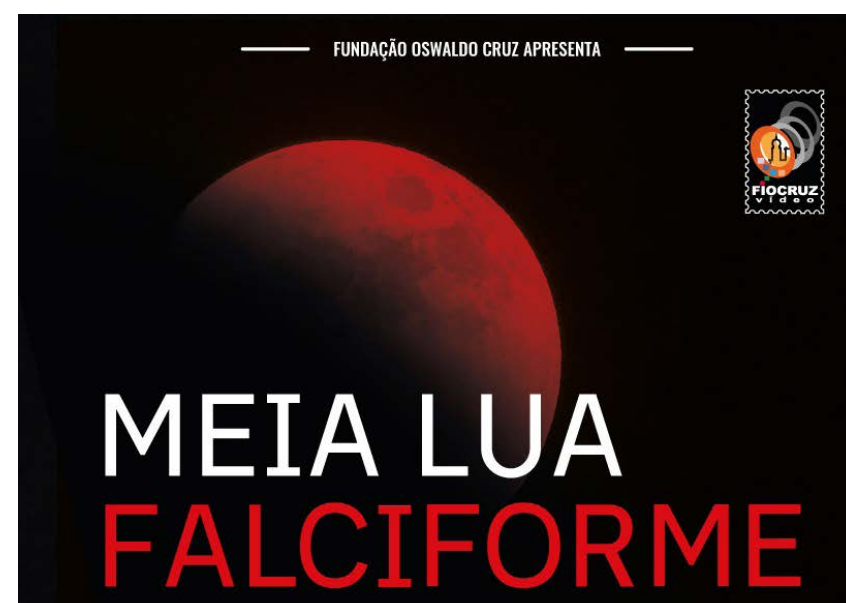

Olhos e ouvidos atentos para relatos carregados de emoção

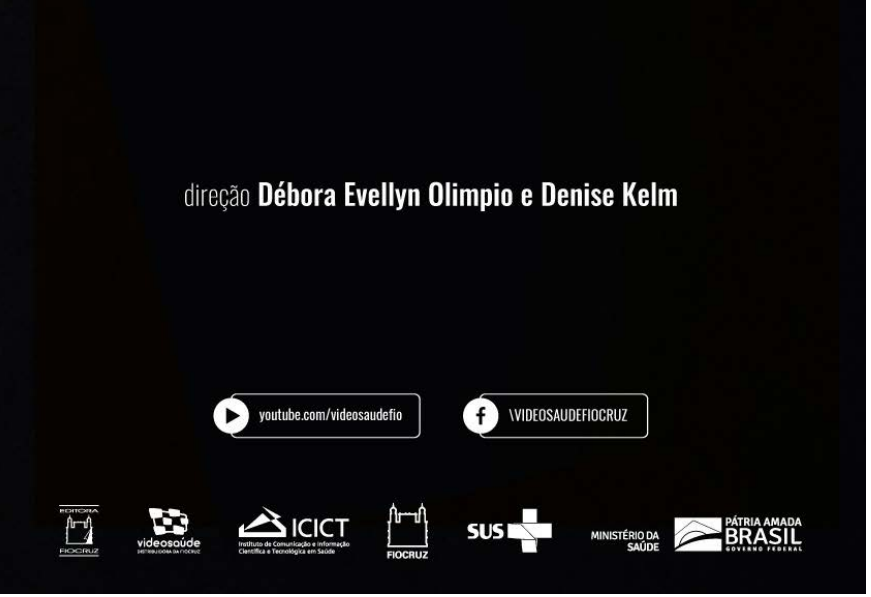

\section{RESUMO}

O documentário Meia lua Falciforme retrata diversas faces e enfrentamentos no cotidiano dos pacientes e familiares que convivem com a doença falciforme no cenário brasileiro. A dor, o racismo e a resistência são pontos-chave discutidos no relevante curta-metragem, de Débora Evellyn Olimpo e Denise Kelm, que traz uma perspectiva para além do adoecimento físico e, com leveza, apresenta produções artísticas dos conviventes com a temática. No tocante à resistência e à luta, o documentário cita a grande conquista no que diz respeito ao reconhecimento e à normatização da doença no Brasil, os conflitos enfrentados rotineiramente em busca 
de acesso aos serviços de saúde, bem como a luta por um SUS que garanta os princípios da universalidade e equidade. A presente resenha traz algumas notas sobre o documentário e os temas que perpassam a vida dos pacientes desde o momento do diagnóstico até os itinerários e decisões terapêuticos.

Palavras-chave: Doença falciforme; Dor; Racismo institucional; Saúde da população negra; Saúde pública.

\section{ABSTRACT}

The documentary entitled Meia lua Falciforme portrays different aspects and daily battles in the life of patients and their families who live with sickle cell disease in the Brazilian scenario. Pain, racism and resistance are key issues discussed in the relevant short-length film by Débora Evellyn Olimpo and Denise Kelm, which brings a perspective that extends beyond the physical illness, and presents in a dainty way some artistic productions of those living with the matter. The documentary mentions the great success regarding the resistance and the struggle for the recognition and regulation of the disease in Brazil, the conflicts routinely faced in search of access to health services, as well as the battle for a SUS that guarantees the principles of universality. and equity. This review brings some observations on the documentary and the matters that permeate the life of patients from the moment of diagnosis to the therapeutic itineraries and decisions.

Keywords: Sickle cell disease; Pain; Institucional racism; Health of the black population; Public health.

\section{RESUMEN}

El documental Meia lua Falciforme nos trae diferentes aspectos y enfrentamientos en la vida diaria de los pacientes y sus familiares que viven con la anemia de células falciformes en el escenario brasileño. El dolor, el racismo y la resistencia son puntos clave discutidos en el cortometraje relevante de Débora Evellyn Olimpo y Denise Kelm, que aporta una perspectiva más allá de la enfermedad física y con delicadeza presenta producciones artísticas de quien vive con el tema. Con respecto a la resistencia y la lucha, el documental cita el gran logro en la pelea por el reconocimiento y la regulación de la enfermedad en Brasil, los conflictos habituales que se enfrentan en busca del acceso a los servicios de salud, así como la lucha por un SUS que garantice los principios de universalidad. y equidad. Esta reseña trae algunas notas sobre el documental y los temas que atravesan la vida de los pacientes desde el momento del diagnóstico, hasta los itinerarios terapéuticos y las decisiones tomadas.

Palabras clave: Anemia de las células falciformes; Dolor; Racismo institucional; Salud de la población negra; Salud Pública.

INFORMAÇÕES DO ARTIGO

Ficha técnica do documentário resenhado:

Título: Meia lua Falciforme: olhos e ouvidos atentos para relatos carregados de emoção.

Direção: Débora Evellyn Olimpio e Denise Kelm.

Produção: VideoSaúde Distribuidora da Fiocruz.

Data de lançamento: 06 de dezembro de 2019.

Duração: 22 minutos.

Contribuição dos autores: a autora é responsável por todo o texto.

Declaração de conflito de interesses: não há

Fontes de financiamento: Bolsa de doutorado da Coordenação de Aperfeiçoamento de Pessoal de Nível Superior (Capes).

Considerações éticas: não há.

Agradecimentos/Contribuições adicionais: À agência de fomento Capes, e às diretoras Débora Evellyn Olimpio e Denise Kelm pelo incrível trabalho e iniciativa na produção deste material tão relevante para a temática da doença falciforme. Dedico também especial agradecimento a Karla Menezes.

Histórico do artigo: submetido: 8 jun. 2020 | aceito: 12 jun. 2020 | publicado: 17 dez. 2020.

Apresentação anterior: não houve.

Licença CC BY-NC atribuição não comercial. Com essa licença é permitido acessar, baixar (download), copiar, imprimir, compartilhar, reutilizar e distribuir os artigos, desde que para uso não comercial e com a citação da fonte, conferindo os devidos créditos de autoria e menção à Reciis. Nesses casos, nenhuma permissão é necessária por parte dos autores ou dos editores. 
O documentário Meia lua Falciforme, de Débora Evellyn Olimpio e Denise Kelm, retrata de forma atenciosa e fiel a realidade dos pacientes e conviventes com a doença falciforme no Brasil. Com a contraposição de um olhar sensível, traz as asperezas enfrentadas no cotidiano dos conviventes com a doença genética mais frequente em nosso país. O curta-metragem, lançado em 2019, conta com a participação de pacientes, mães e personalidades expoentes na temática como a médica Joice Aragão de Jesus, coordenadora emérita da Política Nacional de Atenção Integral às Pessoas com Doença Falciforme.

Traçando um paralelo com a trajetória de vida das pessoas com a doença falciforme, o documentário aborda temas cruciais que devem ser tratados, discutidos e interpelados ao longo da vida dos pacientes, desde o momento do nascimento até as decisões terapêuticas na fase adulta.

A importância do diagnóstico precoce é ressaltada pela médica Joice Aragão como um dos caminhos fundamentais para a melhora da qualidade de vida dos pacientes e para a redução dos quadros infecciosos na primeira infância. Atualmente, a doença falciforme é diagnosticada por meio do teste do pezinho, que faz parte do Programa Nacional Triagem Neonatal' ${ }^{1}$, e as crianças diagnosticadas são encaminhadas a programas multiprofissionais de apoio ao paciente e familiares, aumentando significativamente as medidas profiláticas em relação aos sintomas e à qualidade de vida dos conviventes com a doença.

O documentário apresenta na fala de Joice Aragão a grande conquista da luta que levou ao reconhecimento e normatização da doença dentro do Sistema Único de Saúde e do Ministério da Saúde. A partir deste êxito, em 2005, o emprego de verbas e recursos para tratamento, pesquisa e até o desenvolvimento de políticas se tornou uma realidade possível.

A maternidade também é abordada no documentário de maneira assertiva. O relato de uma mãe que luta com a intensa tarefa de criar seu filho com a doença falciforme expressa as dificuldades encontradas nos serviços de saúde e os aspectos emocionais relacionados com o apoio ao filho acometido por uma enfermidade crônica e suas peculiaridades.

Em outra perspectiva, a paternidade também é relatada no curta-metragem e polemizada pelos entrevistados. Por ser uma doença genética, a culpabilização dos pais pode ser uma constante na trajetória dos conviventes com a doença falciforme. A responsabilidade de transmitir os genes da doença se torna questionável pelos pacientes e familiares, mas também pelos profissionais de saúde. Segundo os relatos, as equipes de saúde utilizam uma suposta baixa expectativa de vida como justificativa para se recuar em relação a parentalidade.

O aconselhamento genético, uma das premissas propostas pela Política Nacional de Atenção às Pessoas com Doença Falciforme e outras Hemoglobinopatias ${ }^{2}$ de 2005, dispõe sobre as opções para os conviventes com a temática, mas afirma que ele não deve ser realizado de forma impositiva ou parcial. Porém, os relatos dos pais entrevistados apontam para um aconselhamento tendencioso e desanimador.

A dor, condição categórica e constante enfrentada pelos pacientes, também é abordada no documentário. Um relato descreve a dificuldade de enquadrar a dor sofrida em uma escala de medição e nos protocolos de dor utilizados (ou não) pelos profissionais de saúde. Apesar de cada paciente a sentir de uma maneira e com intensidade diferentes, a dor segue como o referencial para a doença falciforme, assim como o tratamento para esse sintoma com seus temidos opioides.

A opiofobia, cunhada como a aversão ao uso de medicamentos opiáceos, pode surgir por parte de alguns profissionais de saúde, pelos quais os pacientes são vistos como dependentes químicos ao procurarem os serviços de saúde com quadros de extrema dor ${ }^{3}$. Essa situação, além da condição dolorosa pode impelir ao descaso e à banalização da dor, como apontado por uma entrevistada. O documentário apresenta esta triste realidade que perpassa a rotina dos pacientes com a doença falciforme e interfere diretamente em seus itinerários terapêuticos.

A falta de informações sobre a doença e seus sintomas, segundo alguns relatos apresentados, pode expor os conviventes com a doença falciforme a situações vexatórias, como no caso do priapismo, uma condição de 
ereção peniana involuntária e dolorosa, que pode durar por horas, não acompanhada de desejo ou estímulo sexual. Como complicações de um tratamento indevido, a disfunção erétil pode ser uma realidade4.

Abordar o priapismo no contexto da doença falciforme é considerado como um grande tabu em nossa sociedade e entre os profissionais de saúde, pois parte-se do princípio de que se trata da sexualidade do homem negro e não de um sintoma grave, expondo o paciente a situações de escárnio e humilhação. Um forte caso relatado no curta-metragem, por Joice Aragão, cita um jovem submetido a condutas policiais por acreditarem que seu priarismo poderia ser uma tentativa de estupro e não a expressão da sintomatologia de uma doença genética.

É inegável os efeitos deletérios do desconhecimento da doença falciforme na vida de seus pacientes e familiares. Uma forte sensibilização dos profissionais de saúdee da sociedade em geral seria de grande eficácia na redução da mortalidade, na melhoria da qualidade de vida dos conviventes, evidenciando principalmente a redução dos tratamentos equivocados e a exposição a situações vexatórias e discriminatórias.

Designa-se a origem da doença falciforme ao continente africano e a um processo de resistência à malária. A forte expressão da doença nas Américas se deve à migração forçada de pessoas escravizadas durante o processo de colonização. A despeito do processo de miscigenação no Brasil, a doença falciforme ainda é mais frequente na população negra, mesmo que não exclusivamente, sendo esta população colocada em situação de marginalização e de alarmadas desigualdades sociais e econômicas na sociedade brasileira.

A doença falciforme, em seu contexto racial, pode expor seus pacientes e familiares a diversas formas de discriminação e preconceito. O racismo institucional no Brasil, citado por Jurema Werneck ${ }^{5}$ e outros relevantes estudiosos da temática, pode ser definido como uma falha organizacional na prestação de serviços profissionais devido à cor da pele, à origem étnico-racial ou à cultura da pessoa atendida. Os relatos apresentados no curta-metragem deixam claro a forma pela qual o racismo institucional pode acarretar negligências, às vezes irreversíveis. Como exemplo, tem-se o caso da paciente Maria Vilela que viu de perto a vida do irmão ser ceifada por falta de conhecimento sobre a doença e descaso nos espaços de saúde.

Um forte conflito é gerado quando se aborda o racismo institucional no Sistema Único de Saúde, que tem por princípios doutrinários a universalidade e equidade como propostas norteadoras de todo o sistema e seu serviço de atendimento. A visibilização da doença falciforme, a garantia de acesso à saúde para seus pacientes e a luta pelo fim do racismo institucional são pautas que unem a doença falciforme e o nosso SUS. Como afirma Joice Aragão em Meia lua Falciforme: "Defender o SUS é defender a doença falciforme, defender a doença falciforme é defender o SUS".

O documentário também aborda outra questão bastante discutida no cenário da doença falciforme no Brasil, assim como em toda a pauta sobre saúde da população negra, o quesito raça/cor nos formulários de saúde. Esse instrumento se faz de forte relevância por conseguir identificar, quantificar e reconhecer as inequidades dentro do sistema de saúde para então direcionar medidas práticas e reais na redução dessas desigualdades.

O depoimento apresentado no curta-metragem ainda descreve a apreensão dos profissionais de saúde ao levantarem questões raciais no momento do atendimento, restando apenas prontuários não preenchidos ou preenchidos inadequadamente. Ainda sobre o quesito raça/cor, o relato aponta para a necessidade de se compreender as doenças mais frequentes e prevalentes em determinados grupos genéticos, assim como a importância dessa informação para tratamentos mais diretivos e eficazes.

As questões raciais vinculadas à doença falciforme também aparecem no discurso de Joice Aragão, ao relatar as dificuldades de apresentar projetos e de conseguir que sejam direcionadas verbas para esta frequente enfermidade. Segundo a médica, as autoridades responsáveis pela pauta representavam um padrão branco, de alta classe e pouco sensível à temática étnico-racial e à saúde da população negra.

O caso expressivo do paciente Elvis Magalhães também é abordado no documentário. Elvis foi um dos pioneiros no transplante de medula óssea como possibilidade de cura da doença falciforme no Brasil. 
O transplante, os riscos e seu sucesso são biografados de maneira virtuosa pelo paciente. O receio e o temor do transplante aparecem nas narrativas de outros entrevistados.

Em contraponto ao grande peso da convivência com a doença falciforme no Brasil, o curta-metragem Meia lua Falciforme traz a leveza de uma poesia escrita por Alessandra Reis que, com admirável sensibilidade, aborda a realidade de conviver com a doença falciforme. A expressão artística de uma paciente, onde suas pinturas retratam o cotidiano, as dores e a resistência no contexto do adoecimento também é apresentada.

O discurso dos entrevistados também coincide ao abordarem a falta de escuta ativa dos médicos e profissionais envolvidos no tratamento da doença falciforme. Sensibilidade, humanidade, compreensão da complexidade e do grande peso, físico e emocional, que os sintomas podem acarretar, são características fundamentais entre os profissionais de saúde para um atendimento eficaz e humanizado nos serviços de saúde.

O curta-metragem de Débora Evellyn e Denise Kelm se faz mais que relevante, se faz necessário em todo o cenário atual de luta e defesa do Sistema Único de Saúde. Assim como a luta diária dos pacientes e familiares pelo reconhecimento da doença falciforme, pelo acesso a tratamentos adequados sem descaso ou menosprezo da parte dos profissionais de saúde. Seja pela origem étnica, seja pelo medicamento utilizado, todos os conviventes com a doença merecem respeito e dignidade ao serem tratados dentro de um sistema de saúde.

\section{REFERÊNCIAS}

1. Ministério da Saúde (BR). Programa Nacional de Triagem Neonatal (Internet). Brasília: O Ministério; [2019] [citado em 2020 out. 05]. Disponível em: https://www.gov.br/pt-br/servicos/habilitar-se-noprograma-nacional-de-triagem-neonatal.

2. Ministério da Saúde (BR). Portaria no 1.391, de 16 de agosto de 2005. Institui no âmbito do Sistema Único de Saúde, as diretrizes para a Política Nacional de Atenção Integral às Pessoas com Doença Falciforme e outras Hemoglobinopatias. Brasília; O Ministério: 2005 [citado em 2020 out. 5]. Disponível em: http://bvsms.saude.gov.br/bvs/saudelegis/gm/2005/prt1391_16 08 2005.html.

3. Kulkamp IC, Barbosa CG, Bianchini KC. Percepção de profissionais de saúde sobre aspectos relacionados à dor e utilização de opióides: um estudo qualitativo. Ciên Saúde Coletiva [Internet]. 2008 [citado em 2020 out. 05];13(sup):721-31. Disponível em: https://www.scielo.br/pdf/csc/v13s0/a22v13s0.pdf.

4. Vicari P, Figueiredo MS. Priapismo na doença falciforme. Rev Bras Hematol Hemoter [Internet] 2009 [citado em 2020 out. 05];29(3):275-78. Disponível em: https://www.scielo.br/pdf/rbhh/v29n3/ v29n3a16.pdf.

5. Werneck J. Racismo institucional e saúde da população negra. Saúde Soc [Internet]. 2016 [citado em 2020 out. 05];25(3):535-49. Disponível em: https://www.scielo.br/pdf/sausoc/v25n3/1984-0470sausoc-25-03-00535.pdf. 